5. Thomas, G. A., Jalsovszky, G., Ladd, J. A. and Orville-Thomas, W. J. J. Mol. Struct. 8 (1971) 1.

6. Robinson, D. Z. J. Chem. Phys. 19 (1951) 881.

7. Larsson, R. and Nunziata, G. Acta Chem. Scand. 24 (1970) 1.

8. Zachariasen, W. H. and Plettinger, H. A. Acta Cryst. 12 (1959) 526.

9. Negita, H., Tanaka, T., Okuda, T. and Shimada, H. Inorg. Chem. 5 (1966) 2126.

10. Akishin, P. A., Spiridonov, V. P. and Khudchenkov, A. N. Zh. Fiz. Khim. 33 (1959) 20.

11. Person, W. B. and Hall, L. C. Spectrochim. Acta 20 (1964) 771 .

Received January 18, 1972.

\section{Studies of Crystals of}

\section{2,6-Disubstituted Polyphenylene} Ethers with a Scanning Electron Microscope

\section{ANTTI SAVOLAINEN and JORMA RAUTAVUORI}

\section{Department of Wood and Polymer Chemistry, University of Helsinki, Malminkatu 20, Helsinki, Finland}

$\mathrm{B}_{\mathrm{r}}^{\mathrm{a}}$ arrales-Rienda crystallized poly(2,6-dimethyl-1,4-phenylene ether) (PPO)* from $\alpha$-pinene and obtained a melting point of $507 \mathrm{~K}$ for the polymer crystals. ${ }^{1} \mathrm{He}$ also investigated the crystals with an optical microscope, but as far as we know, no high-resolution studies of the crystals have been conducted with a scanning electron microscope (SEM). In order to elucidate the crystalline structure of PPO and also that of the analogous poly(2,6-dimethoxy-1,4phenylene ether) (PPOO), we have studied crystals of the mentioned polymers by the SEM technique and compared details of the micrographs with the results of DSC measurements.

* PPO is a trademark of the General Electric Co., U.S.A.
Experimental. PPO, $\left(\overline{\mathrm{M}}_{\mathrm{v}}=40000\right)$, a commercial product from General Electric Co., was dissolved in $\alpha$-pinene ${ }^{1}$ and PPOO, $\left(\overline{\mathrm{M}}_{\mathrm{v}}=\right.$ 70000 ), synthesized as described in Ref. 2 , in cyclohexanone. After dissolution of the PPO sample, the solution was held at $353 \mathrm{~K}$ for 5 days. The solution of the PPOO sample was stored at room temperature for the same period of time. After the crystals of PPO had been separated from $\alpha$-pinene, they were washed several times with ether and dried under vacuum. Cyclohexanone was removed from the crystalline PPOO in a Hösli HT 125 vacuum desiccator. The samples (about $5 \mathrm{mg}$ ) were coated with a layer of gold about $200 \AA$ thick and soanned with a Jeolco JSM-U3 scanning electron microscope. The tilting angle of the specimen was $45^{\circ}$. Calorimetric studies were carried out with a Perkin-Elmer 1B differential scanning calorimeter. The weight of the PPOO sample was $15 \mathrm{mg}$ and the scan speed $16^{\circ} / \mathrm{min}$.

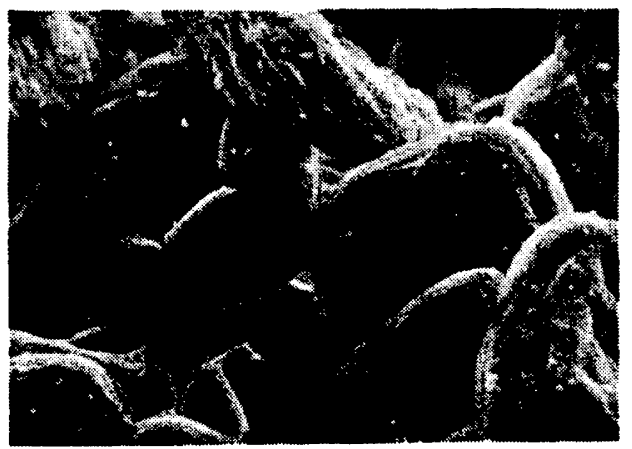

Fig. 1a. Crystals of PPO $(6000 \times)$.

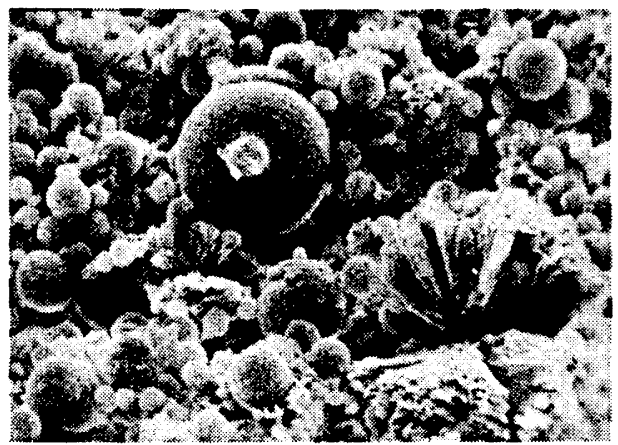

Fig. 1b. Crystals of PPOO $(4500 \times)$.

Acta Chem. Scand. 26 (1972) No. 2 
Discussion and results. Fig. 1a shows that all the crystals of PPO are hedritic. The micrograph of PPOO in Fig. 1b shows that two different types of crystals, partly dendrites and partly spheres, are formed during the crystallization. In DSC analysis PPO gives only one endothermic peak at $507 \mathrm{~K}^{1}$ whereas PPOO gives two peaks at

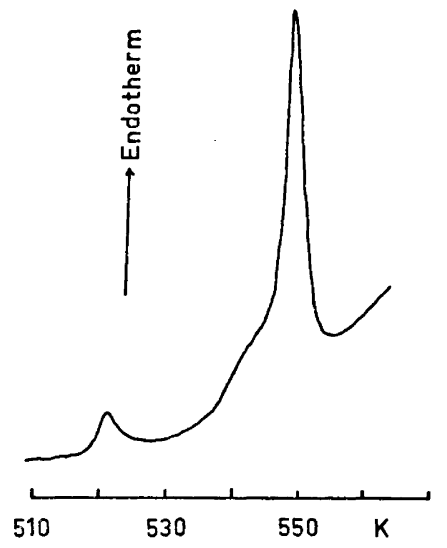

Fig. 2. DSC thermogram of PPOO. Endothermic peaks occur at $523 \mathrm{~K}$ and $549 \mathrm{~K}$.

$523 \mathrm{~K}$ and $549 \mathrm{~K}$ (Fig. 2). It can be assumed that these endothermic peaks of PPOO correspond to the two different crystalline forms.

The work is being continued.

Acknowledgements. We would like to thank Prof. J. Johan Lindberg and Dr. J. Wartiovaara (The Electron Microscope Laboratory, University of Helsinki) for several enlightening discussions. One of the authors (A.S.) is grateful to the Neste Oy Foundation for a grant.

1. Barrales-Rienda, I. M. and Fatou, J. M. G. Kolloid Z. Z. Polym. 244 (1971) 317.

2. Savolainen, A. Poly(2,6-dimetoksi-1,4fenyleenieetterin) ja sen derivaattien synteesi ja ominaisuudet, Thesis, University, Helsinki 1970.

Received November 26, 1971.

\section{Dissociation Constants of Thio- malic Acid in Aqueous Potas- sium Chloride Solutions \\ OSMO MÄKITIE and AULIS ILVONEN}

Department of Chemistry, University of Helsinki, SF-00170 Helsinki 17, Finland

\begin{abstract}
In connection with studies on metal complex formation by thiomalic acid, $\mathrm{HOOC} \cdot \mathrm{CHSH} \cdot \mathrm{CH}_{2} \cdot \mathrm{COOH}$ (mercaptosuccinic acid), the dependence of the dissociation constants of the acid on ionic strength with potassium chloride as the neutral salt was studied potentiometrically.
\end{abstract}

Table 1. Potentiometrically determined dissociation constants of thiomalic acid at $25^{\circ} \mathrm{C}$. The calculated values were obtained by means of eqns. $4-6$.

\begin{tabular}{|c|c|c|c|}
\hline \multicolumn{2}{|c|}{ Observed } & \multicolumn{2}{|c|}{ Calculated } \\
\hline$I$ & $\mathrm{p} K_{1}$ & $\mathrm{p} K_{1}$ & $\mathrm{p} K_{1}^{\circ}$ \\
\hline 0.005 & 3.375 & 3.372 & 3.435 \\
\hline 0.203 & 3.231 & 3.235 & 3.429 \\
\hline 0.504 & 3.214 & 3.220 & 3.428 \\
\hline 1.003 & 3.249 & 3.238 & 3.445 \\
\hline \multirow[t]{2}{*}{2.004} & 3.306 & 3.310 & 3.430 \\
\hline & $\mathrm{p} K_{2}$ & $\mathrm{p} K_{2}$ & $\mathrm{p} K_{2}^{\circ}$ \\
\hline 0.006 & 4.880 & 4.872 & 5.020 \\
\hline 0.011 & 4.828 & 4.830 & 5.010 \\
\hline 0.020 & 4.751 & 4.779 & 4.984 \\
\hline 0.031 & 4.750 & 4.735 & 5.026 \\
\hline 0.211 & 4.502 & 4.504 & 5.010 \\
\hline 0.511 & 4.457 & 4.418 & 5.050 \\
\hline 1.011 & 4.366 & 4.408 & 4.970 \\
\hline \multirow[t]{2}{*}{2.011} & 4.516 & 4.506 & 5.024 \\
\hline & $\mathrm{p} K_{3}$ & $\mathrm{p} K_{3}$ & $\mathrm{p} K_{3}^{\circ}$ \\
\hline 0.012 & 10.872 & 10.848 & 11.167 \\
\hline 0.018 & 10.763 & 10.791 & 11.115 \\
\hline 0.030 & 10.678 & 10.707 & 11.114 \\
\hline 0.038 & 10.718 & 10.664 & 11.198 \\
\hline 0.219 & 10.212 & 10.254 & 11.102 \\
\hline 0.519 & 10.051 & 10.036 & 11.159 \\
\hline 1.020 & 9.918 & 9.906 & 11.155 \\
\hline 2.019 & 9.870 & 9.876 & 11.138 \\
\hline
\end{tabular}

Acta Chem. Scand. 26 (1972) No. 2 